Review Article

\title{
A literature review on depression and its risk factors among people suffering from chronic obstructive pulmonary disease in Asian sub-continent
}

\author{
Amrit Sharma* \\ Department of Community Health, Christian Medical College, Vellore, Tamil Nadu, India \\ Received: 03 August 2020 \\ Accepted: 16 September 2020 \\ *Correspondence: \\ Dr. Amrit Sharma, \\ E-mail: sharma.amrit169gmail.com \\ Copyright: (c) the author(s), publisher and licensee Medip Academy. This is an open-access article distributed under \\ the terms of the Creative Commons Attribution Non-Commercial License, which permits unrestricted non-commercial \\ use, distribution, and reproduction in any medium, provided the original work is properly cited.
}

\begin{abstract}
Chronic obstructive pulmonary disease (COPD) is defined as persistent airflow limitation that is usually progressive and associated with an enhanced chronic inflammatory response in the airways and the lung to noxious particles or gases. It has been suggested that emotional disturbances such as depression and anxiety are common among patients with COPD. This review aims to highlight the presence of depression and associated risk factors among patients suffering from COPD in Asia. Fifty-eight observational studies were retrieved through data sources like PubMed, Medical subject heading (MeSH) search and Google scholar. After thorough screening total thirteen studies were identified and included in this review. Based on the results of these studies, the south and west Asian countries had higher proportion of depression. However, risk factor results were mixed which includes severity of obstruction/global initiative for obstructive lung disease (GOLD) criteria, Stage 2 COPD, teetotallers, smoking, alcohol consumption, body mass index, airflow obstruction, dyspnoea, and exercise (BODE) index, urban residence, female gender, education level, dyspnoea, low income, poor Quality of life (QOL) scores, age, poor self-reported health, basic activity of daily living (BADL) disability. Further superior research studies with larger sample size are required on Asian population. All in all, it is recommended that early diagnosis and treatment of depression should be included as a part of management in COPD as it can help to minimize the risk of morbidity and mortality in the patients.
\end{abstract}

Keywords: COPD, Noxious, MeSH, GOLD, BODE, Dyspnoea

\section{INTRODUCTION}

The GOLD describes COPD as a common, preventable and treatable disease that is characterized by persistent respiratory symptoms and airflow limitation that is due to airway and/or alveolar abnormalities usually caused by significant exposure to noxious particles or gases. ${ }^{1}$ By 2030, COPD is expected to be the third leading cause of death in the world. $^{2}$ The burden of COPD in Asia is currently greater than that in developed western countries, both in terms of the total number of deaths and the burden of disease, as measured in years of life lost and the number of years spent living with a disability and is mainly linked to the epidemic of tobacco exposure and indoor and outdoor air pollution in Asian countries. ${ }^{3}$ According to the latest report on global burden of disease, Asia constitutes $7.65 \%$ of total deaths due to COPD. The fatalities due to COPD were highest in North Korea (17.64\%) followed by Nepal (9.84\%), India (9.67\%), China (9.24\%), Bhutan (8.55\%) and Bangladesh (7.28\%) respectively. ${ }^{4}$ COPD being a chronic, progressive disease poses a huge economic burden on the patient as well as the health-care systems. ${ }^{5}$ At the individual level, it frequently proves to be financially ruin-some for families with average income. The economic burden of direct costs for respiratory diseases is greater in countries with 
lower wages (India $28 \%$ of average wages, Korea $4 \%$, and Singapore 2\%). ${ }^{6}$ It has long been suggested that emotional disturbances such as depression and anxiety are common among patients with COPD, which has a detrimental effect on the quality of life as they affect emotional, social and physical functioning. ${ }^{7}$ Besides this, depression is associated with social stigma and selfstigma, which act as a barrier to the help-seeking behavior. ${ }^{8}$ Symptoms of depression may have widespread consequences for COPD patients. For instance, symptoms of depression not only increase hospitalization and emergency visits by $48 \%$ and $77 \%$, respectively, in COPD patients, but also doubles the likelihood of dying from the comorbidities of COPD- related depression. ${ }^{9,10}$ Therefore, depression has become a matter of great public health concern for COPD patients and their families. The objective of this article aims to highlight the presence of depression, and its risk factors in patients suffering from COPD in Asia.

\section{Search strategy and study selection}

A comprehensive search for the current review was conducted using search engines PubMed (MeSH) and Google scholar in July 2020. All the papers published from 2005-2020 in the English language were considered. The search terms used included 'COPD', 'Chronic obstructive pulmonary disease', 'depression', 'Asia' and derivative terms. Boolean operators 'and, 'or, 'not were used to make search more specific and accurate. The selection of studies retrieved from the electronic databases was completed in distinct stages based on inclusion and exclusion criteria. Initially, duplications were removed. Then, titles and abstracts of articles were reviewed. The remaining articles were then screened by reading and review the full-text articles to decide on the final articles to be included.

Observational studies conducted in Asia and published in a peer-review journal in the English language, Studies reported either prevalence/incidence or risk factors, and measured odds' ratio, relative risk or p-value to show the positive association of variables with the depression, Studies in which subjects were selected from outpatient clinics from primary, secondary or tertiary care; community or random population-based samples, COPD diagnosis confirmed by spirometry: post- bronchodilator FEV1/FVC $<0.7$ and studies used standard scales for the measurement of depression were included for this review.

Table 1: Most relevant research articles included in the literature review.

\begin{tabular}{|c|c|c|c|c|c|}
\hline Author & Study design & $\begin{array}{l}\text { Sample } \\
\text { size }\end{array}$ & $\begin{array}{l}\text { Depression } \\
\text { scale }\end{array}$ & Location & Journal \\
\hline $\begin{array}{l}\text { Tze Pin Ng } \\
\text { et al }{ }^{11}\end{array}$ & Population-based & 2402 & GDS-15 & Singapore & Respiratory medicine \\
\hline $\begin{array}{l}\text { Asnaashari } \\
\text { et al (2012) }\end{array}$ & Cross-sectional & 100 & BDI & Iran & $\begin{array}{l}\text { Iranian Journal of allergy, } \\
\text { asthma, and immunology }\end{array}$ \\
\hline $\begin{array}{l}\text { Bhowmik et } \\
\text { al }(2012)^{13}\end{array}$ & Cross-sectional & 214 & PHQ-9 & India & $\begin{array}{l}\text { South East Asia Journal of } \\
\text { Public Health }\end{array}$ \\
\hline $\begin{array}{l}\text { Lou et al } \\
(2012)^{14}\end{array}$ & Case-control & 2200 & HAD-S & China & BMC pulmonary medicine \\
\hline $\begin{array}{l}\text { Nobuyuki et } \\
\text { al }(2013)^{15}\end{array}$ & Cross-sectional & 82 & GDS-SF & Japan & Respiratory care \\
\hline $\begin{array}{l}\text { Negi et al } \\
(2014)^{16}\end{array}$ & Cross-sectional & 126 & PHQ-9 & India & $\begin{array}{l}\text { Indian Journal of Medical } \\
\text { Research }\end{array}$ \\
\hline $\begin{array}{l}\text { Barua et al } \\
(2015)^{17}\end{array}$ & Cross-sectional & 317 & PHQ-9 & Bangladesh & $\begin{array}{l}\text { Journal of Shaheed Suhrawardy } \\
\text { Medical College }\end{array}$ \\
\hline $\begin{array}{l}\text { Tan et al } \\
(2015)^{18}\end{array}$ & $\begin{array}{l}\text { Prospective } \\
\text { descriptive survey }\end{array}$ & 204 & HAD-S & Philippines & $\begin{array}{l}\text { Philippine Journal of Internal } \\
\text { Medicine }\end{array}$ \\
\hline $\begin{array}{l}\text { Thapa et al } \\
(2017)^{19}\end{array}$ & $\begin{array}{l}\text { Observational } \\
\text { comparative } \\
\text { analytical cohort }\end{array}$ & 198 & BDI & Nepal & BMC Psychiatry \\
\hline $\begin{array}{l}\text { Lee et al } \\
(2018)^{20}\end{array}$ & Cross-sectional & 211 & PHQ-9 & South Korea & International Journal of COPD \\
\hline $\begin{array}{l}\text { Agarwal et } \\
\text { al }(2018)^{21}\end{array}$ & Cross-sectional & 150 & $\begin{array}{l}\text { PHQ-9 and } \\
\text { HAD-S }\end{array}$ & India & $\begin{array}{l}\text { Monaldi archives for chest } \\
\text { disease }\end{array}$ \\
\hline $\begin{array}{l}\text { Zohal et al } \\
(2019)^{22}\end{array}$ & Cross-sectional & 100 & BDI & Iran & $\begin{array}{l}\text { European Journal of } \\
\text { Therapeutics }\end{array}$ \\
\hline $\begin{array}{l}\text { Acharya et } \\
\text { al }(2020)^{23}\end{array}$ & Cross-sectional & 131 & BDI & Nepal & $\begin{array}{l}\text { Nepal journal of medical } \\
\text { sciences }\end{array}$ \\
\hline
\end{tabular}

GDS-15: 15-item Geriatric Depression Scale, PHQ-9: Patient Health Questionnaire, BDI: Beck Depression Inventory, GDS-SF: Geriatric Depression Scale, HAD-S: Hamilton Depression rating scale. 
Table 2: Prevalence and risk factors of depression reported by retrieved studies.

\begin{tabular}{|c|c|c|}
\hline Authors & Prevalence $(\%)$ & Risk factors \\
\hline Tze-Pin Ng et al ${ }^{11}$ & 22.8 & $\begin{array}{l}\text { - BADL disability }(\mathrm{OR}=2.89, \mathrm{p}=0.049) \\
\text { - Poor or fair self-reported health }(\mathrm{OR}=3.35, \mathrm{p}=0.004) \\
\text { - Poor SF-12 PCS and SF-12 MCS scores }(\mathrm{OR}=2.35, \mathrm{p}=0.041 \text { and } \\
\mathrm{OR}=4.17, \mathrm{p}<0.001)\end{array}$ \\
\hline Asnaashari et al $^{12}$ & 54.2 & - Severity of pulmonary obstruction $(\mathrm{p}=0.000)$ \\
\hline Bhowmik et al ${ }^{13}$ & 86 & $\begin{array}{l}\text { - Urban residence }(O R=4.79, p=0.02) \\
\text { - Income group of } I N R / 5000-9999 \text { per Month }(O R=18, p=0.38) \\
\text { - Teetotallers }(O R=8.36, p=0.02) \\
\text { - Stage } 2 \text { COPD }(O R=83, p=0.001) \\
\text { - Onset of COPD }>=70 \text { Years of age }(O R=20, p=0.02)\end{array}$ \\
\hline Lou et $\mathbf{a l}^{14}$ & 35.7 & $\begin{array}{l}\text { - Younger age }(\mathrm{OR}=1.13, \mathrm{p}=0.003) \\
\text { - Female sex }(\mathrm{OR}=1.12, \mathrm{p}<0.001) \\
\text { - Higher education level }(\mathrm{OR}=1.09, \mathrm{p}=0.012) \\
\text { - Lower household income }(\mathrm{OR}=1.26, \mathrm{p}<0.001) \\
\text { - History of smoking }(\mathrm{OR}=1.26, \mathrm{p}<0.001) \\
\text { - BODE index }(\mathrm{OR}=1.51, \mathrm{p}<0.001) \\
\text { - SGRQ }(\mathrm{OR}=1.47, \mathrm{p}<0.001)\end{array}$ \\
\hline Horita et al ${ }^{15}$ & 38.1 & $\begin{array}{l}\text { - } \mathrm{BODE} \text { index }(\mathrm{OR}=2.3, \mathrm{p}<0.001) \\
\text { - } \operatorname{mMRC}(\mathrm{OR}=3.6, \mathrm{p}<0.001)\end{array}$ \\
\hline Negi et al ${ }^{16}$ & $\begin{array}{l}\text { Mild to severe } \\
(49.2) \\
\text { Moderately severe } \\
\text { to severe }(20.6)\end{array}$ & $\begin{array}{l}\text { - Lower educational status }(\mathrm{p}<0.01) \\
\text { - Higher Dyspnoea }(\mathrm{p}<0.01) \\
\text { - GOLD COPD severity }(\mathrm{p}=0.002)\end{array}$ \\
\hline Tan et $\mathbf{a l}^{17}$ & 31.37 & Not Reported \\
\hline Barua et al ${ }^{18}$ & 81.6 & $\begin{array}{l}\text { - Literate } \\
(\mathrm{OR}=13.722, \mathrm{p}=0.001)\end{array}$ \\
\hline Thapa et al ${ }^{19}$ & $\begin{array}{l}\text { Mild }(15.1) \\
\text { Moderate }(44.1) \\
\text { Severe }(35.5)\end{array}$ & - Age $(\mathrm{p}<0.05)$ \\
\hline Lee et $\mathbf{a l}^{20}$ & 14.2 & $\begin{array}{l}\text { - Female sex }(\mathrm{OR}=1.79, \mathrm{p}<0.01) \\
\text { - Living alone }(\mathrm{OR}=1.86, \mathrm{p}<0.01) \\
\text { - Low income }(\mathrm{OR}=2.17, \mathrm{p}<0.01)\end{array}$ \\
\hline Agarwal et al.21 & 30.67 & $\begin{array}{l}\text { - Age group } 61-70 \text { yrs }(\mathrm{p}=0.002) \\
\text { - Smokes } 22 \text { packs/year }(\mathrm{p}=0.002) \\
\text { - History of smoking } 2 \text { years back }(\mathrm{p}=0.002) \\
\text { - mMRC grade } 4(\mathrm{p}=0.015) \\
\text { - GOLD grade } 4(\mathrm{p}=0.038)\end{array}$ \\
\hline Zohal et al $^{22}$ & 75 & $\begin{array}{l}\text { - Smoking }(\mathrm{p}=0.004) \\
\text { - } \operatorname{GOLD}(\mathrm{p}=0.01)\end{array}$ \\
\hline Acharya et $\mathbf{a l}^{23}$ & 78.6 & $\begin{array}{l}\text {-Alcohol consumption } \\
(\mathrm{OR}=3.09, \mathrm{p}<0.01)\end{array}$ \\
\hline
\end{tabular}

SF-12 PCS and MCS: 12 item short form- Physical health component summary score and Mental health component summary score for Quality of life, BADL disability: Basic activities of daily living for functional disability, BODE index: Body-mass index, airflow Obstruction, Dyspnea, and Exercise index, SGRQ: St. George's Respiratory Questionnaire, mMRC: (Modified Medical Research Council) Dyspnoea Scale, GOLD: Global initiative for Obstructive Lung Disease criteria.

Excluded the study design other than observational such as literature reviews, opinion papers, qualitative studies, posters and letters and studies with a sample size of less than 20 participants, also full-text papers not available within the review period and studies conducted on hospitalized patients.

A detailed diagram of the review process is presented in figure 1. The initial search results in PubMed (MeSH) and after google scholar showed 58 articles from which 38 articles were excluded based on the title and abstract. Screening of remaining full-text articles was done one by one based on which 7 articles were excluded with reason. Hence, 13 studies identified after meeting the criteria for the literature review which is shown in Table 1. All the studies included in this review have reported the prevalence to estimate the magnitude of depression. On the other hand, except one study, most of the studies 
determined the predictive factors of depressive symptoms. Authors have used the odds ratio and/or pvalue to show the association which can be seen in Table 2. Majority of participants involved in the research studies were males and old aged. Out of studies included in the literature review three studies were from India; two each from Nepal, Iran; one each from Singapore, South Korea, Japan, China, Philippine, and Bangladesh respectively.

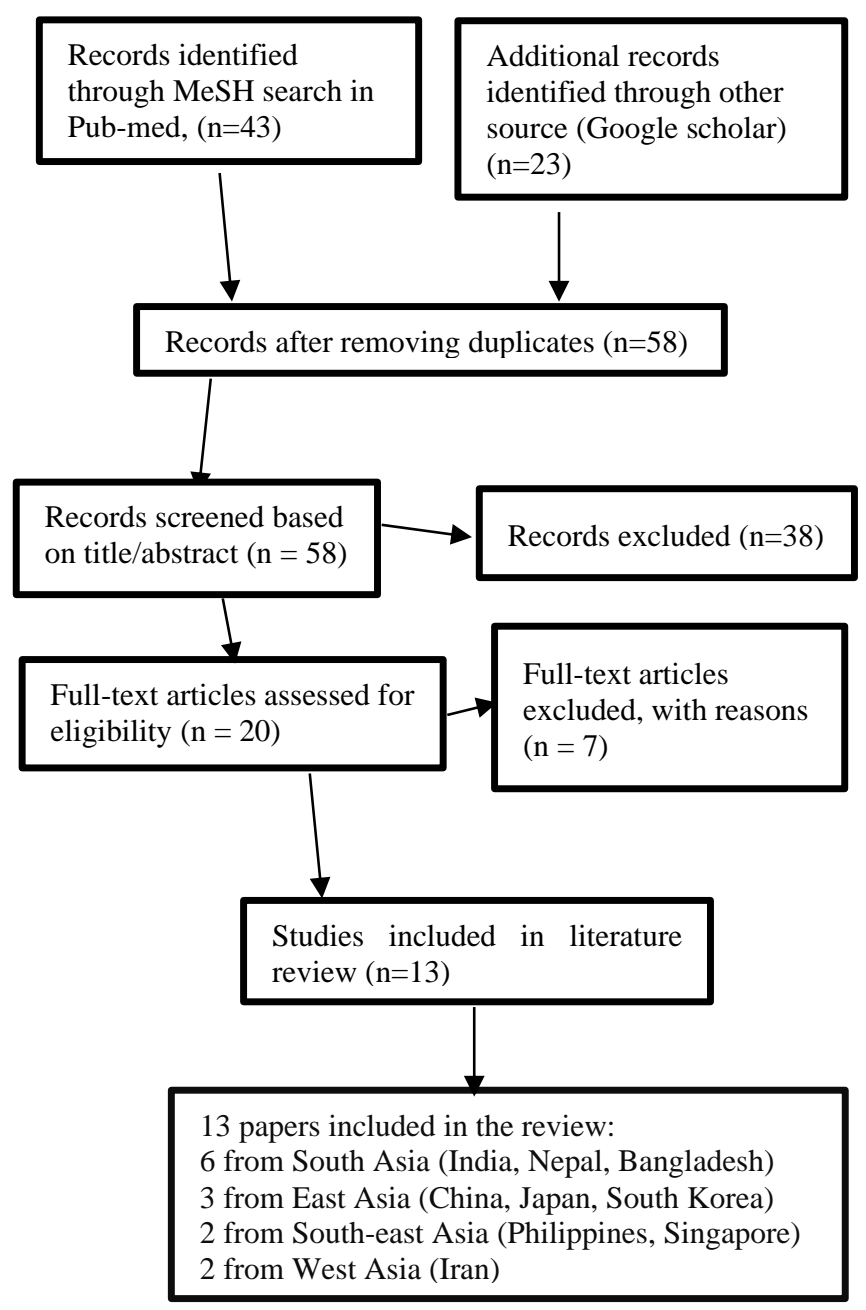

Figure 1: Flow-chart showing review process.

\section{DISCUSSION}

The present literature review shows the proportion of depression and the associated risk factors among COPD patients. The review was conducted using data from the studies of nine Asian countries that fulfilled our criteria. The findings show heterogeneity among studies which was likely due to quantitative (different sample sizes and ratios between COPD subjects and controls) and qualitative disparities (source of subjects, COPD severity, instruments used do screen depression, smoking status, and comorbidities).
Observational studies conducted in three South Asian countries namely, India, Bangladesh and Nepal showed highest proportion of depression among COPD patients with $86 \%, 81.6 \%$ and $78.6 \%$ respectively. ${ }^{13,17,23}$ However, similar study done in India by Agarwal et al presented much lesser prevalence $(30.67 \%)$ which contradicts with the former results. ${ }^{21}$ Furthermore, Thapa et. al and Negi et. al summarized that $35.5 \%$ and $20.6 \%$ were respectively suffered with severe depression. ${ }^{19,16}$ But, another study showed only $4.7 \%$ were severely depressed. ${ }^{17}$

It was reported that $35.7 \%$ and $38.1 \%$ found having depression in East Asian population. ${ }^{14,15}$ On the contrary, study done by Lee et al concluded that depression among COPD patients was almost less than half of that reported by earlier studies in the similar region. ${ }^{20}$ Moreover, both the studies done in Iran suggested, higher prevalence of morbidity (75\% and $54.2 \%$ ). Other than this, studies from Singapore and Philippines included in the present review stated that prevalence was $22.8 \%$ and $31.37 \% \cdot{ }^{11,17}$ Nevertheless, another author conducted multicentric research study in three south-east Asian countries which determined prevalence of depressive features were $62.1 \% .^{24}$

\section{Risk factors}

The analysis done in few studies described that the severity of COPD or GOLD criteria was statistically significant in the development of depression. ${ }^{12,16,21,22}$ Besides this, Bhowmik et al interpreted that stage 2 COPD patients had high chance of developing depression. ${ }^{13}$ On comparing, Barua et al reported that the stage 2 COPD is less likely to cause psychiatric illness. ${ }^{18}$

Smoking and alcohol consumption were found significant factors. ${ }^{14,22,23}$ However, one study reported that teetotaller patients had almost 8.36 times more chance of getting depression than those with habits. ${ }^{13}$ Moreover, another author from India determined that the patient who smokes atleast 22 bundles of cigarette/beedi per year had significant chance of developing depression. ${ }^{21}$ Also, results of the study by Horita et al supported the findings of previous study. ${ }^{15}$

Research based in India reported that the COPD patients residing in urban areas were significantly associated with the depression. ${ }^{13}$ On the other hand, similar study rejected the hypothesis of association of depression with the area of residence. ${ }^{16}$ Moreover, Lou et al and Lee et al said that female gender was a statistically significant risk factor.

Higher education level and literate has shown positive association. $^{14,18}$ On the other side, another study concluded that lower education level was factor responsible for depression. ${ }^{16}$ Furthermore, study from China and Japan revealed that dyspnoea level is possibly a risk factor. ${ }^{14,15}$ Likewise, another author from South Asia reported, the significant association of depressive 
symptoms with higher dyspnoea and mentioned reduced physical activity due to dyspnoea as a primary factor that had led to psychiatric morbidity. ${ }^{16}$

Lower income was said to be the risk factor by Lou et al. and Lee et al. ${ }^{14,20}$ However, survey conducted India suggested that income group of 5000-9999 INR per Month had 18 times higher chances of having depression than patients of other income groups. ${ }^{13}$

Population-based study done in Singapore concluded, poor quality of life scores were significantly associated with higher chances of depression in an individual. ${ }^{11}$ Other than this, age has shown high odd's especially patients with $>70$ years. ${ }^{19,14}$ However, one author came to the inference that younger age had significant association. ${ }^{13}$ As per results patients having poor selfreported health were 3.35 times more likely to encounter depression and also those with functional disability had higher chances of developing mental issues. ${ }^{11}$

The strengths of this literature review are the use of several criteria to select the studies. For instance, only patients with COPD diagnosed by spirometry were selected aiming to avoid dissimilarities in COPD diagnosis. Moreover, the influence of studies that can impact the results like patients who were hospital admitted or institutionalized were excluded.

There are possible limitations in this review. First, many of the reviewed studies were cross-sectional and retrospective in design, meaning that neither directionality nor causality could be reliably inferred from the results. Second, the participant in most of the studies reviewed were predominantly male. Third, the sample size in most of the studies was small which limits the interpretation of the results. Fourth, only two sources were used to search articles with language restriction. Lastly, in few studies' COPD patients had other comorbidities which might have affected mental health of the patients.

\section{CONCLUSION}

Findings from this literature review reveals that the COPD patients in Asian sub-continent suffer from depression, comparatively higher in the people of south and west Asian countries. The prevalence of and the risk factors that affect depression differ depending on cultural backgrounds and assessment methods. Further research studies with larger sample size are required on Asian population. It is recommended that early assessment and comprehensive treatment of depression should be included as a part of management in COPD as it can help to achieve better therapeutic outcomes for the patients.

Funding: No funding sources

Conflict of interest: None declared

Ethical approval: Not required

\section{REFERENCES}

1. Global Initiative for Chronic Obstructive Lung Disease. Global strategy for the diagnosis management and prevention of Chronic Obstructive Pulmonary disease. Report, 2018. Available at https:/goldcopd.org/wp-content/uploads/ 2017/11/GOLD-2018-v6.0-FINAL-revised-20-

Nov_WMS.pdf. Accessed 1 July 2020.

2. www.who.int world bank / WHO global burden of disease study. Accessed on 2 July 2020.

3. Lopez AD, Mathers CD, Ezzati M. Global and regional burden of disease and risk factors, 2001: systematic analysis of population health data. Lancet. 2006; 367:1747-57.

4. Global burden of disease compares, 2017. Available at https://vizhub.healthdata.org/gbd-compare/. Accessed on 5 July 2020.

5. SK Jindal, COPD: The Unrecognized Epidemic in India, JAPI, 2012;60:14-6.

6. Wang DY, Ghoshal AG, Muttalif ARBA, Lin HC, Thanaviratananich S, Bagga et al. Quality of life and economic burden of respiratory disease in AsiaPacific-Asia-pacific burden of respiratory diseases study. Value Health Reg Issues. 2016;9:72-7.

7. Vogele C, von Leupoldt V. Mental disorders in chronic obstructive pulmonary disease (COPD), Respiratory Medicine. 2008;102:764-73.

8. Farooq S, Khan T, Zaheer S, Shafique K. Prevalence of anxiety and depressive symptoms and their association with multimorbidity and demographic factors: a community-based, cross-sectional survey in Karachi, Pakistan. BMJ Open. 2019; 9(11):029315.

9. Dalal AA, Shah M, Lunacsek O, Hanania NA. Clinical and economic burden of depression/anxiety in chronic obstructive pulmonary disease patients within a managed care population. COPD. 2011;8:293-9.

10. De Voogd JN, Wempe JB, Koëter GH, Postema K, Van Sonderen E, Ranchor AV et al. Depressive symptoms as predictors of mortality in patients with COPD. Chest. 2009;135(3):619-25.

11. Ng TP, Niti M, Fones C, Yap KB, Tan W-C. Comorbid association of depression and COPD: A population-based study. Respiratory Medicine. 2009;103(6):895-901.

12. Asnaashari AMH, Talaei A, Haghighi M B. Evaluation of Psychological Status in Patients with Asthma and COPD. Iran J Allergy Asthma Immunol. 2012;11(1): 65-71.

13. Bhowmik KM, Adhikari A, Choudhury S, Ahmed MM. Prevalence of depression and its risk factors among patients with chronic obstructive pulmonary disease in a tertiary level hospital in West Bengal, India. South East Asia J pub Health. 2013;2(2):3440.

14. Lou P, Zhu Y, Chen P, Zhang P, Yu J, Zhang N et al. Prevalence and correlations with depression, anxiety, and other features in outpatients with chronic obstructive pulmonary disease in China: a cross- 
sectional case control study. BMC Pulmonary Med. 2012;12:53.

15. Horita N, Kaneko T, Shinkai M, Yomoto M, Morita S, Rubin B K et al. Depression in Japanese patients with chronic obstructive pulmonary disease: a crosssectional study. Respir Care. 2013;58(7):1196-1203.

16. Negi H, Sarkar M, Raval AD, Pandey K, Das P. Presence of depression and its risk factors in patients with chronic obstructive pulmonary disease. Indian $\mathbf{J}$ Med Res. 2014;139(3):402-8.

17. Barua U, Ghosh D, Biswas A, Nath M, Biswas B, Saha $\mathrm{N}$ et al. Depression and Its Risk Factors Among Patients with Chronic Obstructive Pulmonary Disease (COPD) in a Tertiary Level Hospital. J Shaheed Suhrawardy Med Col. 2017;7(2): 44-8.

18. Tan SM, Benedicto JP, Santiaguel JM. Prevalence of anxiety and depression among Filipino patients with chronic obstructive pulmonary disease: A multicenter study. Philippine J Internal Med. 201553(1): 34-48.

19. Niresh T, Muna M, Tirtha S, Srijana G, Prakash P, Yam T. Anxiety and depression among patients with chronic obstructive pulmonary disease and general population in rural Nepal. BMC Psychiatry. 2017; 17:397.

20. Lee JH, Park MA, Park MJ, Jo YS. Clinical characteristics and related risk factors of depression in patients with early COPD. Int J Chron Obstruct Pulmon Dis. 2018;13:1583-1590.

21. Agarwal A, Batra S, Prasad R, Verma A, Jilani AQ, Kant SA. study on the prevalence of depression and the severity of depression in patients of chronic obstructive pulmonary disease in a semi-urban Indian population. Monaldi ArchChest Dis. 2018;88(1):902.

22. Zohal M, Mohammadi L, Shamloo F, Javadi A, Yazdi Z. Prevalence and Associated Depression Risk Factors in Patients with Chronic Obstructive Pulmonary Disease in Qazvin, Iran (2014). Eur J Ther. 2019;25(3):159-63.

23. Acharya CP, Poudel K, Thapaliya R. Anxiety and Depression among Patients with Chronic Obstructive Pulmonary Disease. Nepal J Med Sci. 2020;5(1):3544.

24. Peltzer K. Pengpid S. Anxiety and depressive features in chronic disease patients in Cambodia, Myanmar and Vietnam. S Afr J Psychiat. 2016;22(1):940.

Cite this article as: Sharma A. A literature review on depression and its risk factors among people suffering from chronic obstructive pulmonary disease in Asian sub-continent. Int J Community Med Public Health 2020;7:4653-8. 